\title{
Role of Twist and Podoplanin in Partial Epithelial-Mesenchymal Transition in Oral Squamous Cell Carcinoma
}

Larissa Santos Amaral Rolim ${ }^{1}$, Rodrigo Porpino Mafra $^{1}{ }^{\circledR}$, Hellen Bandeira de Pontes Santos ${ }^{2}{ }^{\circledR}$, Lélia Batista de Souza ${ }^{1 \odot}$, Leão Pereira Pinto ${ }^{1}{ }^{\circledR}$
'Postgraduate Program in Oral Sciences, Department of Dentistry, UFRN - Universidade Federal do Rio Grande do Norte, Natal, RN, Brazil

${ }^{2}$ Postgraduate Program in Health Family, FACENE - Faculdade Nova Esperança, João Pessoa, PB, Brazil

Correspondence: Leão Pereira Pinto, Avenida Senador Salgado Filho, 1787, 59056-000 Natal, RN, Brasil. Tel: +55-84-3215-4138. e-mail: lp.pinto@hotmail.com

\begin{abstract}
The aim of this study was to perform a comparative analysis of podoplanin (PDPN) and Twist immunoexpressions in lower lip and oral tongue squamous cell carcinomas (LLSCC and OTSCC, respectively). PDPN and Twist immunoexpressions were semi-quantitatively evaluated by analyzing the invasion front, the compressive areas, the large islands and nests and dissociated cells of the chosen carcinomas. Their statistical associations and correlations with clinical-pathological characteristics were verified by the Mann-Whitney and Spearman's test. Twist expression was low in both carcinomas, with $<25 \%$ labeling on the invasive front. Significant differences were observed for LLSCC $(p=0.032)$ and OTSCC $(p=0.025)$ regarding PDPN immunoexpression in relation to the worst invasion patterns determined by a histological malignancy gradation system. Statistically significant negative correlations between PDPN membrane expression and general $(r=-0.356, p=0.024)$ and cytoplasmic Twist expressions ( $r=-0.336 ; p=0.034)$ in LLSCC were also observed. Twist and PDPN are suggested to be associated to a more aggressive invasion pattern in both LLSCC and OTSCC cases but not related to the different biological behaviors on these anatomical sites. Also, it was seen that PDPN membrane expression is inversely related to general and cytoplasmic Twist expression in LLSCC cases.
\end{abstract}

Key Words: twist, podoplanin, epithelial-mesenchymal transition, oral pathology.

\section{Introduction}

Oral Squamous Cell Carcinomas (OSCC) are the most common type of head and neck cancer, representing 90\% of all types of oral cancer, and whose poor prognosis is compromising, considering the high frequency of regional lymph node metastases due to local invasion. In this context, the search for prognostic markers represents a continuous challenge for research in the biomedical sciences $(1,2)$.

Tumor progression is triggered by malignant cells that have detached from the primary tumor, forming, initially, regional and, subsequently, distant metastases. It is believed that this mechanism occurs by the collective invasion of cell groups or individual cells, in an Epithelial-Mesenchymal Transition (EMT) scenario. In a cancer context, EMT, which is mostly associated to the individual invasion process, represents a process by which tumor cells lose their original epithelial phenotype and acquire mesenchymal cell characteristics. This process is accompanied by the decreased expression of specific epithelial biomarkers, such as E-cadherin, $\beta$-catenin and occludin, followed by increased expression of mesenchymal biomarkers, such as Twist, Zeb, Snail and Vimentin, with the simultaneous occurrence of increased cell migration and invasion potential, cytoskeleton remodeling and apoptosis resistance $(3,4)$. The collective invasion mechanism, on the other hand, involves groups of neoplastic cells that collectively separate from the primary tumor, leading to metastasis. Podoplanin (PDPN) is a transmembrane glycoprotein related to cell contractile properties. It promotes cytoskeleton reorganization, and it is assumed that it coordinates a number of cells to undergo a partial EMT, allowing for orientation of the adherent cell complex (3).

Considering the different clinical courses that lower lip squamous cell carcinoma (LLSCC) and oral tongue squamous cell carcinoma (OTSCC) present $(1,5)$, the role of PDPN and Twist in these SCCs is not yet fully understood. In addition, to date, no previous studies have investigated and compared invasion mechanisms related to these proteins simultaneously in LLSCCS and OTSCCS, as well as the relationship between PDPN and Twist in oral carcinogenesis. Thus, the present study aimed to analyze PDPN and Twist immunoexpression profiles in LLSCC and OTSCC cases and evaluate their relationship with clinical-pathological parameters, aiming to better understand their role in the development of these tumors.

\section{Material and Methods Samples}

Sampling was intentional and non-probabilistic, consisting of 76 SCC tissue specimens obtained exclusively 
from surgical resection fixed in $10 \%$ formaldehyde, embedded in paraffin and stored at the Pathology Department of the Dr. Luiz Antônio Hospital, Natal/RN, Brazil. A total of 40 LLSCC and 36 OTSCC cases were selected. Only SCC specimens treated by surgical resection, without previous radiotherapy or chemotherapy, with sufficient biological material, were included. The data of interest for the study were obtained from patient medical charts. The study was approved by the local Ethics Committee (Liga Norte Riograndense Contra o Câncer/Approval No. 2.092.526).

\section{Morphological Analysis}

Tissue specimens of the selected cases, fixed in 10\% formaldehyde and embedded in paraffin were cut into $5-\mu m$-thick histological sections, placed on histological slides and stained with hematoxylin and eosin (HE). The specimens were analyzed by a single researcher previously trained by an experienced pathologist.

The histological malignancy grading analysis was performed based on the system parameters proposed by Brandwein-Gensler et al. (6) evaluating the worst invasion pattern, host lymphocytic response on the front of tumor $\Xi$ invasion and perineural invasion.

\section{Immunohistochemistry}

For the immunohistochemical analysis, 3- $\mu \mathrm{m}$ thick sections were mounted on organosilane (3-aminopropyltriethoxysilane; Sigma Chemical Co., St. Louis, MO, USA) coated slides. Primary mouse monoclonal antibodies against PDPN (D2-40, 1:400, overnight, Dako, Carpinteria, CA, USA) and Twist (015672, 1:1000, 60', Boster Biological Technology, Pleasanton, CA, USA) were applied. After antigen recovery, endogenous peroxidase was blocked with a 1:1 methanol and 3\% hydrogen peroxidase solution. Antibodies were detected by staining with immunoperoxidase using the dextran polymer-based signal intensification technique (ADVANCE ${ }^{\mathrm{TM}}$, Dako). The reaction was developed with diaminobenzidine as chromogen. Negative controls consisted of primary antibody replacement by bovine serum albumin.

The slides were subsequently scanned and immunohistochemical evaluations were carried out (Pannoramic MIDI, 1.15SPI,3D HISTECH ${ }^{\circledR}$, Budapest, Hungary). As in morphological analysis, immunohistochemistry analysis was performed by a single researcher previously trained by an experienced pathologist. Analyses of the tumor invasion fronts, compressive areas, large tumor islands ( $>15$ neoplastic cells) and nests and dissociated cells ( $<15$ neoplastic cells) were carried out for both markers.

The PDPN analysis was carried out semi-quantitatively, adapting the methodology adopted by Prasad et al. (7).
Cells exhibiting brownish staining on the plasma membrane and/or cytoplasm, regardless of intensity, were considered immunopositive, where the following scores were attributed: 0 (0\% - absent expression), 1 (1-25\% positive cells), 2 (26-50\% positive cells) and 3 (>50\% positive cells), concerning membrane, cytoplasmic and membrane + cytoplasm immunostaining. The Twist analysis was also performed semi-quantitatively, adapting the methodology adopted by da Silva et al. (8). Cells exhibiting brownish staining in the nucleus and/or cytoplasm, independent of labeling intensity, were considered immunopositive and the following scores were assigned: 1 ( $<25 \%$ positive cells), 2 (25\%-50\% positive cells), 3 (51-75\% positive cells) and 4 ( $>75 \%$ positive cells), concerning nuclear, cytoplasmic and nucleus + cytoplasm immunostaining.

\section{Statistical Analysis}

The clinical-pathological and immunohistochemical data were submitted to both descriptive and inferential statistics, using the SPSS Statistics 22.0 software (IBM Corp., Armonk, NY, USA). Associations between clinicalpathological parameters and anatomical locations were assessed by Pearson's Chi-Square test and Fisher's Exact test. Comparisons of PDPN and Twist expression medians according to the clinical-histopathological parameters were analyzed by the non-parametric Mann-Whitney test. Possible correlations between PDPN and Twist immunoexpressions in the investigated lesions were evaluated by Spearman's non-parametric correlation ( $r$ ) test. A significance level of $5 \%(p<0.05)$ was considered for all statistical tests.

\section{Results}

\section{Clinical and Morphological Data}

All clinical-pathological results are displayed in Table 1. The age groups most affected by the disease were patients over 50 , with means of $66.83 \pm 15.10$ and $61.03 \pm 12.75$ years old for LLSCC and OTSCC, respectively. Regarding clinicalpathological parameters, OTSCC, compared to LLSCCS, presented higher frequencies in characteristics as drinking ( $p=0.001)$, lymph node metastasis $(p=0.001)$, advanced clinical stage $(p=0.011)$, local recurrence $(p=0.002)$, disease outcome $(p=0.003)$, histopathological risk $(p=0.012)$, worst pattern of invasion type IV and $V(p=0.020)$, and perineural invasion $(p<0.001)$. These associations were statistically significant.

When the worst invasion pattern was considered as an isolated variable, a notable predominance of an invasion pattern organized by small islands of tumor cells formed by less than 15 cells or individualized cells (type 4) was observed for both LLSCC (52.5\%) and OTSCC (72.2\%). Comparison of morphological aspects between LLSCC and 
Table 1. Association between anatomical sites (LLSSC and OTSCC) and clinical-pathological parameters

\begin{tabular}{|c|c|c|c|}
\hline \multirow{2}{*}{ Parameters } & \multicolumn{2}{|c|}{ Site } & \multirow[b]{2}{*}{$\mathrm{p}$} \\
\hline & Lower Lip (n=40) [n (\%)] & Oral Tongue $(\mathrm{n}=36)[\mathrm{n}(\%)]$ & \\
\hline \multicolumn{4}{|l|}{ Gender } \\
\hline Male & $30(75.0)$ & $27(75.0)$ & $1.000^{* 1}$ \\
\hline Female & $10(25.0)$ & $9(25.0)$ & \\
\hline \multicolumn{4}{|l|}{ Age $^{a}$} \\
\hline Up to 50 years & $6(15.0)$ & $5(14.3)$ & $0.930^{* 1}$ \\
\hline$>50$ years & $34(85.0)$ & $30(85.7)$ & \\
\hline \multicolumn{4}{|l|}{ Smoking habit ${ }^{\mathrm{b}}$} \\
\hline Yes & $5(19.2)$ & $4(12.1)$ & $0.488^{* 2}$ \\
\hline No & $21(80.8)$ & 29 (87.9) & \\
\hline \multicolumn{4}{|l|}{ Drinking habit ${ }^{\mathrm{c}}$} \\
\hline Yes & $17(68.0)$ & $7(22.6)$ & $0.001^{* 1}$ \\
\hline No & $8(32.0)$ & $24(77.4)$ & \\
\hline \multicolumn{4}{|l|}{ Sun exposure ${ }^{d}$} \\
\hline Yes & $14(35.0)$ & - & - \\
\hline No & $13(32.5)$ & - & \\
\hline \multicolumn{4}{|l|}{ Tumor size } \\
\hline $\mathrm{T} 1 / \mathrm{T} 2$ & $32(80.0)$ & $22(61.1)$ & $0.070^{* 1}$ \\
\hline $\mathrm{T} 3 / \mathrm{T} 4$ & $8(20.0)$ & $14(38.9)$ & \\
\hline \multicolumn{4}{|l|}{ Lymph node metastasis } \\
\hline Absent & $31(77.5)$ & $14(38.9)$ & $0.001^{* 1}$ \\
\hline Present & $9(22.5)$ & $22(61.1)$ & \\
\hline \multicolumn{4}{|l|}{ Distant metastasis } \\
\hline Absent & $40(100.0)$ & $35(97.2)$ & $\#$ \\
\hline Present & $0(0.0)$ & $1(2.8)$ & \\
\hline \multicolumn{4}{|l|}{ Clinical stage } \\
\hline Stage I/ II & $25(62.5)$ & $12(33.3)$ & $0.011^{* 1}$ \\
\hline Stage III/ IV & $15(37.5)$ & $24(66.7)$ & \\
\hline \multicolumn{4}{|l|}{ Local recurrence $^{\mathrm{e}}$} \\
\hline Absent & $39(97.5)$ & $14(66.7)$ & $0.002^{* 2}$ \\
\hline Present & $1(2.5)$ & $7(33.3)$ & \\
\hline \multicolumn{4}{|l|}{ Disease outcome ${ }^{f}$} \\
\hline Remission/ In progress & $35(89.7)$ & $21(58.3)$ & $0.003^{* 2}$ \\
\hline Death due to the tumor & $4(10.3)$ & $15(41.7)$ & \\
\hline \multicolumn{4}{|l|}{ Histopathological risk ${ }^{* * *}$} \\
\hline Low/ intermediate risk & $31(77.5)$ & $18(50.0)$ & $0.012^{* 1}$ \\
\hline High risk & $9(22.5)$ & $18(50.0)$ & \\
\hline \multicolumn{4}{|l|}{ Worst pattern of invasion ${ }^{* * *}$} \\
\hline Type $1 / 2 / 3$ & $15(37.5)$ & $5(13.9)$ & $0.020^{* 1}$ \\
\hline Type $4 / 5$ & $25(62.5)$ & $31(86.1)$ & \\
\hline \multicolumn{4}{|l|}{ Lymphocytic response $^{* *}$} \\
\hline Type 1 & $21(52.5)$ & $16(44.4)$ & $0.483^{* 1}$ \\
\hline Type $2 / 3$ & $19(47.5)$ & $20(55.6)$ & \\
\hline \multicolumn{4}{|l|}{ Perineural invasion*** } \\
\hline Absent & $30(75.0)$ & $9(25.0)$ & $<0.001^{* 1}$ \\
\hline Small/ large nerves & $10(25.0)$ & $27(75.0)$ & \\
\hline
\end{tabular}

LLSCC: lower lip squamous cell carcinoma. OTSCC: oral tongue squamous cell carcinoma. ${ }^{2}$ One case had no information regarding age; bSeventeen cases had no information regarding smoking habit; 'Twenty cases had no information regarding drinking habit; ${ }^{d}$ Thirteen cases had no information regarding sun exposure; eFifteen cases had no information regarding local recurrence; fOne case had no information regarding disease outcome. "Not possible to perform statistical analysis. ${ }^{* 1}$ Pearson's Chi-Square test $(\chi 2) ;{ }^{*}$ Fisher's Exact test. **(Brandwein-Gensler et al., 2005). 
OTSCC, like lymphocytic infiltrate throughout the invasion front, perineural invasion, and different patterns of invasion are displayed in Figure 1.

\section{Immunohistochemical Features \\ LLSCC}

Sixteen (40.0\%) of the LLSCC cases presented $>50 \%$ PDPN immunoexpression staining on the invasion front, in general (immunostaining of both cell compartments: membrane + cytoplasm). Regarding Twist immunoexpression, 13 cases (32.5\%) showed low general (nucleus + cytoplasm) staining, with $<25 \%$ of cells expressing this protein (Fig. 2). It is noteworthy that PDPN staining was predominant in large island peripheries and that decreases in the number of island cells led to increased PDPN staining.

\section{Podoplanin}

No statistically significant differences were found between cytoplasmic, membrane and general PDPN immunoexpression and the analyzed clinical parameters ( $p>0.05)$ in LLSCC cases. Analyzing the histopathological parameters as variables isolated from the grading system proposed by Brandwein Gensler et al. (6), immunoexpression of cytoplasmic PDPN was found to be higher in cases presenting type 4 and 5 invasion patterns $(p=0.032)$. In addition, although non-significantly, higher median values

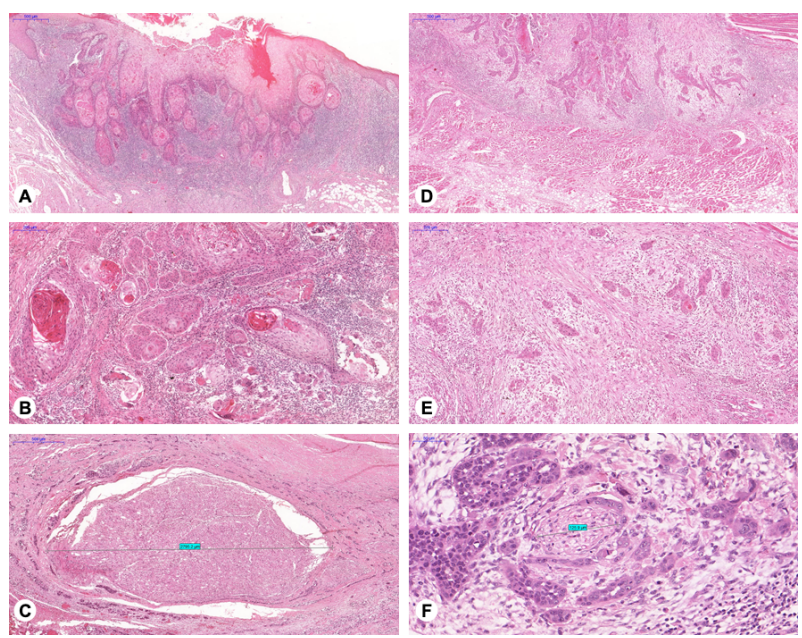

Figure 1 Morphological aspects and different patterns of invasion in LLSCC (A-C) and OTSCC (D-F). A) Dense continuous band of lymphocytic infiltrate throughout the invasion front in LLSCC (HE stain; magnification, $\times 5$ ). B) Pattern of invasion of large tumor islands containing more than 15 cells per island in LLSCC (HE stain; magnification, $\times 5$ ). C) Tumor invasion of large nerves interestingly more seen in LLSCC cases (HE stain; magnification, $\times 5$ ). D) Little lymphocytic response throughout the invasion front in OTSCC (HE stain; magnification, $\times 10$ ). E) Pattern of invasion arranged in small tumor buds formed by less than 15 cells or individualized cells in OTSCC (HE stain; magnification, $\times 5$ ). F) Tumor invasion of small nerves in OTSCC (HE stain; magnification, $\times 20$ ). of membrane $(p=0.234)$ and general $(p=0.060)$ PDPN immunoexpression were observed in LLSCC cases presenting type 4 and 5 invasion patterns (Table 2).

Twist

No statistically significant differences between cytoplasmic, nuclear and general Twist immunoexpression and the analyzed clinical parameters and the grading system proposed by Brandwein Gensler et al. (6) were observed in LLSCC cases ( $p>0.05$ ) (Table 3).

\section{OTSCC}

General PDPN immunoexpression at the invasion front (membrane + cytoplasm immunostaining) was predominantly $>50 \%$ cells throughout the invasion front $(44.4 \%)$ in the evaluated OTSCC cases. General Twist immunoexpression (nucleus + cytoplasm) low in 17 cases (47.2\%), at $<25 \%$ (Fig. 3). It is noteworthy that, as in LLSCC cases, PDPN staining on large islands occurred predominantly on island periphery. As the number of cells decreased in the islands, PDPN staining increased.

\section{Podoplanin}

No statistically significant differences were detected between cytoplasmic, membrane and general PDPN immunoexpression and the analyzed clinical-pathological parameters $(p>0.05)$ in OTSCC cases (Table 4$)$. When evaluating the isolated variables from the grading system proposed by Brandwein Gensler et al. (6), OTSCC cases with type 4 and 5 invasion patterns revealed higher cytoplasmic $(p=0.006)$, membrane $(p=0.030)$ and general $(p=0.025)$ PDPN expression compared to cases presenting type 1 and 2 patterns (Table 4).
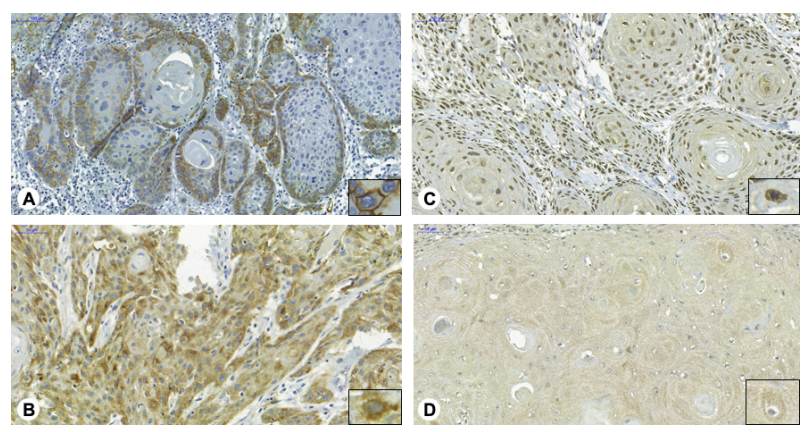

Figure 2 Immunoexpression of PDPN (A and B) and Twist (C and D) in LLSCC. A) Membrane immunoexpression of PDPN on the periphery of the islands (immunohistochemistry stain for PDPN; magnification, $\times 10$ ). B) Cytoplasmic immunoexpression of PDPN (immunohistochemistry stain for PDPN; magnification, $\times 20$ ). C) Nuclear immunoexpression of Twist (immunohistochemistry stain for Twist; magnification, $\times 10$ ). D) Cytoplasmic immunoexpression of Twist (immunohistochemistry stain for Twist; magnification, $\times 20$ ). 


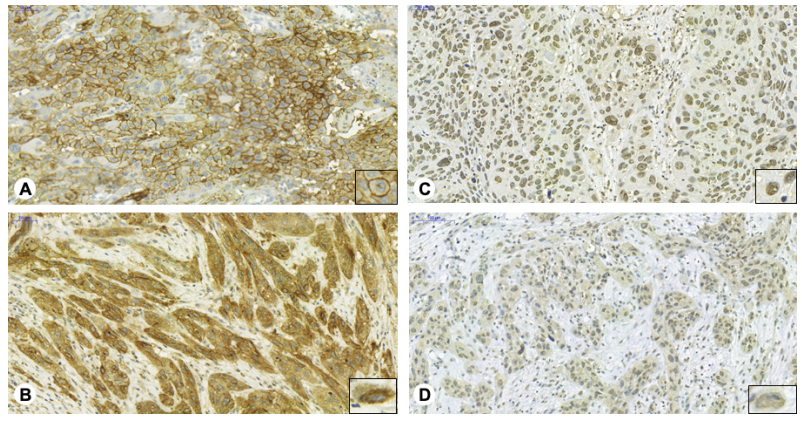

Figure 3 Immunoexpression of PDPN (A and B) and Twist (C and D) in OTSCC. A) Membrane immunoexpression of PDPN (immunohistochemistry stain for PDPN; magnification, ×20). B) Cytoplasmic immunoexpression of PDPN (immunohistochemistry stain for PDPN; magnification, $\times 20$ ). C) Nuclear immunoexpression of Twist (HE stain; magnification, $\times 20$ ). D) Cytoplasmic immunoexpression of Twist (HE stain; magnification, $\times 10$ ).
Twist

No statistically significant differences were found for cytoplasmic, nuclear and general Twist immunoexpressions in relation to the analyzed clinical parameters and the grading system proposed by Brandwein Gensler et al. (6) in OTSCC cases ( $p>0.05$ ) (Table 5).

\section{Correlation between PDPN and Twist immunoexpressions in LLSCC and OTSCC cases}

Spearman's correlation test indicated a statistically significant negative correlation between membrane PDPN expression and general Twist expression $(r=-0.356, p=0.024)$ and between membrane PDPN expression and cytoplasmic Twist expression $(r=-0.336, p=0.034)$ in LLSCC cases. No

Table 2. Analysis of the cytoplasmic, membrane and general immunoexpression scores of PDPN and their differences according to clinicalpathological parameters of LLSCC

\begin{tabular}{|c|c|c|c|c|c|c|c|c|c|c|c|c|c|}
\hline \multirow[b]{2}{*}{ Parameters } & \multirow[b]{2}{*}{$\mathrm{n}$} & \multicolumn{4}{|c|}{ PDPN (cytoplasm) } & \multicolumn{4}{|c|}{ PDPN (membrane) } & \multicolumn{4}{|c|}{ PDPN (general) } \\
\hline & & $\begin{array}{c}\text { Median } \\
\text { (Q25-Q75) }\end{array}$ & $\begin{array}{c}\text { Mean of } \\
\text { ranks }\end{array}$ & $\mathrm{U}$ & $\mathrm{p}^{*}$ & $\begin{array}{c}\text { Median } \\
\text { (Q25-Q75) }\end{array}$ & $\begin{array}{c}\text { Mean of } \\
\text { ranks }\end{array}$ & $\mathrm{U}$ & $\mathrm{p}^{*}$ & $\begin{array}{c}\text { Median } \\
\text { (Q25-Q75) }\end{array}$ & $\begin{array}{c}\text { Mean of } \\
\text { ranks }\end{array}$ & $\mathrm{U}$ & $\mathrm{p}^{*}$ \\
\hline \multicolumn{14}{|l|}{ Tumor size } \\
\hline $\mathrm{T} 1 / \mathrm{T} 2$ & 32 & $2(1-3)$ & 19.23 & 87.50 & 0.151 & $0.5(0-2)$ & 20.98 & 112.50 & 0.567 & $2(1-3)$ & 20.16 & 117.00 & 0.695 \\
\hline $\mathrm{T} 3 / \mathrm{T} 4$ & 8 & $3(2-3)$ & 25.56 & & & $0(0-2)$ & 18.56 & & & $2(2-3)$ & 21.88 & & \\
\hline \multicolumn{14}{|l|}{ Lymph node metastasis } \\
\hline Absent & 31 & $2(1-3)$ & 20.48 & 139.00 & 0.986 & $0(0-2)$ & 19.84 & 119.00 & 0.469 & $2(1-3)$ & 20.53 & 138.50 & 0.973 \\
\hline Present & 9 & $2(0.5-3)$ & 20.56 & & & $1(0-3)$ & 22.78 & & & $2(0.5-3)$ & 20.39 & & \\
\hline \multicolumn{14}{|l|}{ Clinical stage } \\
\hline Stage I/ II & 25 & $2(1-3)$ & 19.82 & 170.50 & 0.618 & $1(0-2.5)$ & 21.58 & 160.50 & 0.410 & $2(1-3)$ & 21.06 & 173.50 & 0.681 \\
\hline Stage III/ IV & 15 & $2(1-3)$ & 21.63 & & & $0(0-2)$ & 18.70 & & & $2(1-3)$ & 19.57 & & \\
\hline \multicolumn{14}{|l|}{ Histopathological risk ${ }^{* * *}$} \\
\hline Low/intermediate risk & 31 & $2(1-3)$ & 20.26 & 132.00 & 0.799 & $0(0-2)$ & 20.92 & 126.50 & 0.646 & $2(1-3)$ & 20.66 & 134.50 & 0.865 \\
\hline High risk & 9 & $2(1-3)$ & 21.33 & & & $0(0-2)$ & 19.06 & & & $2(2-2.5)$ & 19.94 & & \\
\hline \multicolumn{14}{|l|}{ Worst pattern of invasion ${ }^{* *}$} \\
\hline Type $1 / 2 / 3$ & 15 & $1(1-2)$ & 15.63 & 114.50 & 0.032 & $0(0-2)$ & 17.90 & 148.50 & 0.234 & $1(1-3)$ & 16.23 & 123.50 & 0.060 \\
\hline Type 4/ 5 & 25 & $3(1.5-3)$ & 23.42 & & & $1(0-2)$ & 22.06 & & & $2(2-3)$ & 23.06 & & \\
\hline \multicolumn{14}{|l|}{ Lymphocytic response $^{* * *}$} \\
\hline Type 1 & 21 & $2(1-3)$ & 20.62 & 197.00 & 0.943 & $1(0-2)$ & 21.17 & 185.50 & 0.679 & $2(1-3)$ & 20.69 & 195.50 & 0.909 \\
\hline Type $2 / 3$ & 19 & $2(1-3)$ & 20.37 & & & $0(0-2)$ & 19.76 & & & $2(1-3)$ & 20.29 & & \\
\hline \multicolumn{14}{|l|}{ Perineural invasion*** } \\
\hline Absent & 30 & $2(1-3)$ & 19.97 & 134.00 & 0.600 & $0(0-2)$ & 20.58 & 147.50 & 0.932 & $2(1-3)$ & 20.27 & 143.00 & 0.818 \\
\hline Small/Large Nerves & 10 & $2(1.75-3)$ & 22.10 & & & $0.5(0-2.25)$ & 20.25 & & & $2(2-3)$ & 21.20 & & \\
\hline \multicolumn{14}{|l|}{ Local recurrence } \\
\hline Yes & 1 & \# & \# & $\#$ & \# & \# & $\#$ & \# & $\#$ & $\#$ & $\#$ & $\#$ & $\#$ \\
\hline No & 39 & & & & & & & & & & & & \\
\hline \multicolumn{14}{|l|}{ Disease outcome } \\
\hline Remission/In progress & 35 & $2(1-3)$ & 20.71 & 45.00 & 0.226 & $0(0-2)$ & 20.69 & 46.00 & 0.223 & $2(1-3)$ & 20.47 & 53.50 & 0.423 \\
\hline Death due to the tumor & 4 & $1(0.25-2.5)$ & 13.75 & & & $0(0-0.75)$ & 14.00 & & & $1.5(0.25-2.75)$ & 15.88 & & \\
\hline
\end{tabular}

PDPN: podoplanin; LLSCC: lower lip squamous cell carcinoma. *Non-parametric Mann-Whitney test (U). ${ }^{* *}($ Brandwein-Gensler et al., 2005). \# Not possible to perform statistical analysis. 
correlations between general, cytoplasmic and membrane PDPN immunoexpressions and general, cytoplasmic and nuclear Twist expressions in OTSCC cases were observed $(p>0.05)$.

\section{Differences between PDPN and Twist Immunoexpressions in LLSCC and OTSCC}

Cytoplasmic $(p=0.930)$, membrane $(p=0.195)$ and general $(p=0.810)$ PDPN immunoexpressions did not reveal statistically significant differences between LLSCC and OTSCC cases. Similarly, no statistically significant differences were found between both evaluated SCCs, regarding cytoplasmic $(p=0.305)$, nuclear $(p=0.646)$ and general ( $p=0.523)$ Twist immunoexpressions.

\section{Discussion}

The acquisition of a neoplastic cell invasive phenotype is a multi-step process, beginning at the initial stages of the primary tumor sites, encompassing both individual and collective complex cellular mobility and coordinated by several tumor cells and microenvironment interactions $(9,10)$. PDPN plays an essential role in collective cell invasion $(11,12)$. In addition, different mechanisms may contribute to cell migration and dedifferentiation, such as EMT, depending, mostly, on the active remodeling of the cellular cytoskeleton. This phenomenon involves the

Table 3. Analysis of the cytoplasmic, nuclear and general immunoexpression scores of Twist and their differences according to clinical-pathological parameters of LLSCC

\begin{tabular}{|c|c|c|c|c|c|c|c|c|c|c|c|c|c|}
\hline \multirow[b]{2}{*}{ Parameters } & \multirow[b]{2}{*}{$\mathrm{n}$} & \multicolumn{4}{|c|}{ Twist (cytoplasm) } & \multicolumn{4}{|c|}{ Twist (nucleus) } & \multicolumn{4}{|c|}{ Twist (general) } \\
\hline & & $\begin{array}{c}\text { Median } \\
(Q 25-Q 75)\end{array}$ & $\begin{array}{c}\text { Mean } \\
\text { of ranks }\end{array}$ & $\mathrm{U}$ & $\mathrm{p}^{*}$ & $\begin{array}{c}\text { Median } \\
\text { (Q25-Q75) }\end{array}$ & $\begin{array}{l}\text { Mean } \\
\text { of ranks }\end{array}$ & $\mathrm{U}$ & $\mathrm{p}^{*}$ & $\begin{array}{c}\text { Median } \\
(Q 25-Q 75)\end{array}$ & $\begin{array}{c}\text { Mean } \\
\text { of ranks }\end{array}$ & $\mathrm{U}$ & $\mathrm{p}^{*}$ \\
\hline \multicolumn{14}{|l|}{ Tumor size } \\
\hline $\mathrm{T} 1 / \mathrm{T} 2$ & 32 & $1(0-3)$ & 19.17 & 85.50 & 0.141 & $1(1-2)$ & 19.22 & 87.00 & 0.155 & $2(1-3)$ & 19.30 & 89.50 & 0.182 \\
\hline $\mathrm{T} 3 / \mathrm{T} 4$ & 8 & $2(1-4)$ & 25.81 & & & $2.5(1-4)$ & 25.63 & & & $2.5(2-4)$ & 25.31 & & \\
\hline \multicolumn{14}{|l|}{ Lymph node metastasis } \\
\hline Absent & 31 & $1(0-3)$ & 20.32 & 134.00 & 0.855 & $2(1-3)$ & 21.94 & 95.00 & 0.139 & $2(1-3)$ & 21.24 & 116.50 & 0.445 \\
\hline Present & 9 & $2(0.5-3)$ & 21.11 & & & $1(0-2)$ & 15.56 & & & $2(1-2.5)$ & 17.94 & & \\
\hline \multicolumn{14}{|l|}{ Clinical stage } \\
\hline Stage I/ II & 25 & $1(0-2.5)$ & 19.30 & 157.50 & 0.391 & $2(1-2.5)$ & 21.40 & 165.00 & 0.519 & $2(1-3)$ & 20.28 & 182.00 & 0.875 \\
\hline Stage III/ IV & 15 & $2(1-4)$ & 22.50 & & & $1(0-3)$ & 19.00 & & & $2(1-4)$ & 20.87 & & \\
\hline \multicolumn{14}{|l|}{ Histopathological risk ${ }^{* * *}$} \\
\hline Low/intermediate risk & 31 & $1(0-3)$ & 20.21 & 130.50 & 0.765 & $1(1-3)$ & 19.81 & 118.00 & 0.475 & $2(1-3)$ & 19.74 & 116.00 & 0.435 \\
\hline High risk & 9 & $2(1-2.5)$ & 21.50 & & & $2(1-3)$ & 22.89 & & & $3(2-3)$ & 23.11 & & \\
\hline \multicolumn{14}{|l|}{ Worst pattern of invasion ${ }^{* *}$} \\
\hline Type $1 / 2 / 3$ & 15 & $1(0-2)$ & 17.87 & 148.00 & 0.259 & $1(0-2)$ & 17.90 & 148.50 & 0.263 & $2(1-3)$ & 17.63 & 144.50 & 0.218 \\
\hline Type $4 / 5$ & 25 & $2(1-3)$ & 22.08 & & & $2(1-3)$ & 22.06 & & & $2(2-3)$ & 22.22 & & \\
\hline \multicolumn{14}{|l|}{ Lymphocytic response ${ }^{* *}$} \\
\hline Type 1 & 21 & $1(0-3)$ & 17.79 & 142.50 & 0.114 & $1(0.5-2.5)$ & 17.93 & 145.50 & 0.133 & $2(1-3)$ & 18.71 & 162.00 & 0.298 \\
\hline Type $2 / 3$ & 19 & $2(1-3)$ & 23.50 & & & $2(1-3)$ & 23.34 & & & $2(2-3)$ & 22.47 & & \\
\hline \multicolumn{14}{|l|}{ Perineural invasion ${ }^{* *}$} \\
\hline Absent & 30 & $1.5(0.75-3)$ & 20.82 & 140.50 & 0.761 & $1(1-2)$ & 19.63 & 124.00 & 0.404 & $2(1-3)$ & 19.97 & 134.00 & 0.608 \\
\hline Small/ Large Nerves & 10 & $1.5(0-3)$ & 19.55 & & & $2.5(0.75-3)$ & 23.10 & & & $3(0.75-3.25)$ & 22.10 & & \\
\hline \multicolumn{14}{|l|}{ Local recurrence } \\
\hline Yes & 1 & $\#$ & $\#$ & $\#$ & $\#$ & $\#$ & $\#$ & $\#$ & $\#$ & $\#$ & $\#$ & $\#$ & $\#$ \\
\hline No & 39 & & & & & & & & & & & & \\
\hline \multicolumn{14}{|l|}{ Disease outcome } \\
\hline Remission/In progress & 35 & $2(1-3)$ & 19.66 & 58.00 & 0.551 & $2(1-3)$ & 20.69 & 46.00 & 0.229 & $2(1-3)$ & 20.07 & 67.50 & 0.904 \\
\hline $\begin{array}{l}\text { Death due to } \\
\text { the tumor }\end{array}$ & 4 & $2.5(1-4)$ & 23.00 & & & $1(1-1.75)$ & 14.00 & & & $2(1-3.75)$ & 19.38 & & \\
\hline
\end{tabular}

LLSCC: lower lip squamous cell carcinoma. *Non-parametric Mann-Whitney test (U). **(Brandwein-Gensler et al., 2005). "Not possible to perform statistical analysis. 
participation of several proteins, such as the Snail, Twist and Zeb transcription factors, and Vimentin protein frequently activated during tumor development, and highly associated to individual invasion $(13,14)$. In this context, the present study demonstrated for the first time that membrane PDPN expression is inversely related to Twist in LLSCC cases, and that both PDPN and Twist are correlated to a more aggressive pattern in both LLSCC and OTSCC cases, but not related to the different behaviors of SCC in the two different anatomical sites.

Several studies have analyzed the immunoexpression of PDPN regarding the different cell compartments (membrane and cytoplasm) associating with clinicalpathological parameters. Prasad et al. (7) observed that the cytoplasmic expression of PDPN was higher in poorly differentiated OSCC, as was also observed in the membrane expression of PDPN. Association of strong cytoplasmic PDPN immunoexpression and lymph node metastasis in

Table 4. Analysis of the cytoplasmic, membrane and general immunoexpression scores of PDPN and their differences according to clinical-pathological parameters of OTSCC

\begin{tabular}{|c|c|c|c|c|c|c|c|c|c|c|c|c|c|}
\hline \multirow[b]{2}{*}{ Parameters } & \multirow[b]{2}{*}{$\mathrm{n}$} & \multicolumn{4}{|c|}{ PDPN (cytoplasm) } & \multicolumn{4}{|c|}{ PDPN (membrane) } & \multicolumn{4}{|c|}{ PDPN (general) } \\
\hline & & $\begin{array}{l}\text { Median } \\
\left(Q_{25}-Q_{75}\right)\end{array}$ & $\begin{array}{c}\text { Mean of } \\
\text { ranks }\end{array}$ & $\mathrm{U}$ & $\mathrm{p}^{*}$ & $\begin{array}{l}\text { Median } \\
\left(Q_{25}-Q_{75}\right)\end{array}$ & $\begin{array}{c}\text { Mean of } \\
\text { ranks }\end{array}$ & $\mathrm{U}$ & $\mathrm{p}^{*}$ & $\begin{array}{l}\text { Median } \\
\left(Q_{25}-Q_{75}\right)\end{array}$ & $\begin{array}{c}\text { Mean of } \\
\text { ranks }\end{array}$ & $\mathrm{U}$ & $\mathrm{p}^{*}$ \\
\hline \multicolumn{14}{|l|}{ Tumor size } \\
\hline $\mathrm{T} 1 / \mathrm{T} 2$ & 22 & $1(1-3)$ & 17.86 & 140.00 & 0.627 & $1(0-3)$ & 19.07 & 141.50 & 0.625 & $2(1-3)$ & 18.91 & 145.00 & 0.756 \\
\hline T3/ T4 & 14 & $2.5(1-3)$ & 19.50 & & & $1(0-3)$ & 17.61 & & & $2(0.75-3)$ & 17.86 & & \\
\hline \multicolumn{14}{|l|}{ Lymph node metastasis } \\
\hline Absent & 14 & $1(1-3)$ & 17.64 & 142.00 & 0.677 & $1(0-3)$ & 19.93 & 134.00 & 0.488 & $1(0.75-3)$ & 16.79 & 130.00 & 0.407 \\
\hline Present & 22 & $2(1-3)$ & 19.05 & & & $1(0-3)$ & 17.59 & & & $2(1-3)$ & 19.59 & & \\
\hline \multicolumn{14}{|l|}{ Clinical stage } \\
\hline Stage I/ II & 12 & $1(1-3)$ & 15.83 & 112.00 & 0.250 & $1(0-3)$ & 18.67 & 142.00 & 0.943 & $1(1-3)$ & 16.13 & 115.50 & 0.308 \\
\hline Stage III/ IV & 24 & $2.5(1-3)$ & 19.83 & & & $1(0-3)$ & 18.42 & & & $2.5(1-3)$ & 19.69 & & \\
\hline \multicolumn{14}{|l|}{ Histopathological risk ${ }^{* *}$} \\
\hline Low/intermediate risk & 18 & $1.5(1-3)$ & 17.61 & 146.00 & 0.588 & $1(0-3)$ & 18.03 & 153.50 & 0.774 & $2(1-3)$ & 18.28 & 158.00 & 0.893 \\
\hline High risk & 18 & $2(1-3)$ & 19.39 & & & $1(0-3)$ & 18.97 & & & $2(1-3)$ & 18.72 & & \\
\hline \multicolumn{14}{|l|}{ Worst pattern of invasion ${ }^{* *}$} \\
\hline Type $1 / 2 / 3$ & 5 & $1(0-1)$ & 7.30 & 21.50 & 0.006 & $0(0-0.5)$ & 9.60 & 33.00 & 0.030 & $1(0-1.5)$ & 9.30 & 31.50 & 0.025 \\
\hline Type 4/ 5 & 31 & $3(1-3)$ & 20.31 & & & $1(0-3)$ & 19.94 & & & $3(1-3)$ & 19.98 & & \\
\hline \multicolumn{14}{|l|}{ Lymphocytic response ${ }^{* *}$} \\
\hline Type 1 & 16 & $2.5(1-3)$ & 18.50 & 160.00 & 1.000 & $1.5(0-3)$ & 18.69 & 157.00 & 0.919 & $2.5(1-3)$ & 18.72 & 156.50 & 0.905 \\
\hline Type $2 / 3$ & 20 & $2(1-3)$ & 18.50 & & & $1(0-3)$ & 18.35 & & & $2(1-3)$ & 18.33 & & \\
\hline \multicolumn{14}{|l|}{ Perineural invasion ${ }^{* *}$} \\
\hline Absent & 9 & $1(0.5-3)$ & 14.72 & 87.50 & 0.184 & $1(0-3)$ & 17.17 & 109.50 & 0.639 & $1(0.5-3)$ & 15.06 & 90.50 & 0.227 \\
\hline Small/ Large Nerves & 27 & $2(1-3)$ & 19.76 & & & $1(0-3)$ & 18.94 & & & $2(1-3)$ & 15.65 & & \\
\hline \multicolumn{14}{|l|}{ Local recurrence } \\
\hline Yes & 7 & $3(0-3)$ & 11.00 & 49.00 & 1.000 & $0(0-3)$ & 10.43 & 45.00 & 0.741 & $3(0-3)$ & 10.64 & 46.50 & 0.838 \\
\hline No & 14 & $1.5(1-3)$ & 11.00 & & & $1(0-3)$ & 11.29 & & & $2.5(1-3)$ & 11.18 & & \\
\hline \multicolumn{14}{|l|}{ Disease outcome } \\
\hline Remission/In progress & 21 & $2(1-3)$ & 18.21 & 151.00 & 0.837 & $1(0-3)$ & 17.93 & 145.50 & 0.681 & $2(1-3)$ & 18.55 & 156.50 & 0.973 \\
\hline $\begin{array}{l}\text { Death due to } \\
\text { the tumor }\end{array}$ & 15 & $2(1-3)$ & 18.90 & & & $1(0-3)$ & 19.30 & & & $2(1-3)$ & 18.43 & & \\
\hline
\end{tabular}

PDPN: podoplanin; OTSCC: oral tongue squamous cell carcinoma. *Non-parametric Mann-Whitney test $(U) .{ }^{* *}($ Brandwein-Gensler et al., 2005). 
lip SCC was reported by Assao et al. (15). On the other hand, in the study by Garcia et al. (16), strong cytoplasmic and membrane expression of PDPN was associated with higher disease-free survival rates at 5 and 10 years in lip SCC. Regarding the transcription factor Twist, Rasti et al. (17) observed that cytoplasmic expression of Twist1 was associated with higher grade renal cell carcinomas rather than nuclear expression. Taking into account the fact how each protein acts in carcinogenesis regarding its cell location (membrane, cytoplasm and nucleus) is still not a consensus, we decided to investigate the immunoexpression in each cell compartment (membrane and cytoplasmic PDPN; nuclear and cytoplasmic Twist) to delve deeper into the biological role of these proteins in the development

Table 5. Analysis of the cytoplasmic, nuclear and general immunoexpression scores of Twist and their differences according to clinical-pathological parameters of OTSCC

\begin{tabular}{|c|c|c|c|c|c|c|c|c|c|c|c|c|c|}
\hline \multirow[b]{2}{*}{ Parameters } & \multirow[b]{2}{*}{$n$} & \multicolumn{4}{|c|}{ Twist (cytoplasm) } & \multicolumn{4}{|c|}{ Twist (nucleus) } & \multicolumn{4}{|c|}{ Twist (general) } \\
\hline & & $\begin{array}{l}\text { Median } \\
\left(Q_{25}-Q_{75}\right)\end{array}$ & $\begin{array}{c}\text { Mean of } \\
\text { ranks }\end{array}$ & $U$ & $p^{*}$ & $\begin{array}{l}\text { Median } \\
\left(Q_{25}-Q_{75}\right)\end{array}$ & $\begin{array}{c}\text { Mean of } \\
\text { ranks }\end{array}$ & $U$ & $p^{*}$ & $\begin{array}{l}\text { Median } \\
\left(Q_{25}-Q_{75}\right)\end{array}$ & $\begin{array}{c}\text { Mean of } \\
\text { ranks }\end{array}$ & $U$ & $p^{*}$ \\
\hline \multicolumn{14}{|l|}{ Tumor size } \\
\hline $\mathrm{T} 1 / \mathrm{T} 2$ & 22 & $1.5(1-3.25)$ & 18.50 & 154.00 & 1.000 & $1(1-3)$ & 18.57 & 152.50 & 0.956 & $1.5(1-3.25)$ & 18.00 & 143.00 & 0.702 \\
\hline $\mathrm{T} 2 / \mathrm{T} 4$ & 14 & $1.5(1-3.25)$ & 18.50 & & & $1(1-2.25)$ & 18.39 & & & $2(1-3.25)$ & 19.29 & & \\
\hline \multicolumn{14}{|l|}{ Lymph node metastasis } \\
\hline Absent & 14 & $1(1-4)$ & 17.93 & 146.00 & 0.779 & $1(1-4)$ & 19.36 & 142.00 & 0.662 & $2(1-4)$ & 19.29 & 143.00 & 0.702 \\
\hline Present & 22 & $2(1-3)$ & 18.86 & & & $1(1-2.25)$ & 17.95 & & & $1.5(1-3)$ & 18.00 & & \\
\hline \multicolumn{14}{|l|}{ Clinical stage } \\
\hline Stage I/ II & 12 & $2(1-4)$ & 20.42 & 121.00 & 0.403 & $1.5(1-4)$ & 20.75 & 117.00 & 0.309 & $2(1-4)$ & 21.00 & 114.00 & 0.281 \\
\hline Stage III/ IV & 24 & $1(1-2.75)$ & 17.54 & & & $1(1-2)$ & 17.38 & & & $1(1-3)$ & 17.25 & & \\
\hline \multicolumn{14}{|l|}{ Histopathological risk ${ }^{* *}$} \\
\hline $\begin{array}{l}\text { Low/intermediate } \\
\text { risk }\end{array}$ & 18 & $2(1-2.5)$ & 18.94 & 154.00 & 0.784 & $1(1-2)$ & 17.00 & 135.00 & 0.337 & $2(1-2.5)$ & 18.39 & 160.00 & 0.946 \\
\hline High risk & 18 & $1(1-3.25)$ & 18.06 & & & $1.5(1-3)$ & 20.00 & & & $1.5(1-3.25)$ & 18.61 & & \\
\hline \multicolumn{14}{|c|}{ Worst pattern of invasion ${ }^{* *}$} \\
\hline Type $1 / 2 / 3$ & 5 & $1(1-2)$ & 14.70 & 58.50 & 0.347 & $1(1-1)$ & 11.00 & 40.00 & 0.054 & $1(1-2)$ & 14.00 & 55.00 & 0.271 \\
\hline Type 4/ 5 & 31 & $2(1-4)$ & 19.11 & & & $1(1-3)$ & 19.71 & & & $2(1-4)$ & 19.23 & & \\
\hline \multicolumn{14}{|l|}{ Lymphocytic response ${ }^{* * *}$} \\
\hline Type 1 & 16 & $2(1-3.5)$ & 20.94 & 121.00 & 0.179 & $1(1-2)$ & 18.59 & 158.50 & 0.957 & $2(1-3.5)$ & 20.34 & 130.50 & 0.315 \\
\hline Type $2 / 3$ & 20 & $1(1-3)$ & 16.55 & & & $1(1-3)$ & 18.43 & & & $1(1-3)$ & 17.03 & & \\
\hline \multicolumn{14}{|l|}{ Perineural invasion*** } \\
\hline Absent & 9 & $1(1-2)$ & 14.94 & 89.50 & 0.206 & $1(1-1.5)$ & 15.00 & 90.00 & 0.196 & $1(1-2)$ & 15.78 & 97.00 & 0.338 \\
\hline $\begin{array}{l}\text { Small/Large } \\
\text { Nerves }\end{array}$ & 27 & $2(1-4)$ & 19.69 & & & $1(1-3)$ & 19.67 & & & $2(1-4)$ & 19.41 & & \\
\hline \multicolumn{14}{|l|}{ Local recurrence } \\
\hline Yes & 7 & $2(1-4)$ & 12.14 & 41.00 & 0.514 & $1(1-2)$ & 12.21 & 40.50 & 0.426 & $1(1-4)$ & 11.36 & 46.50 & 0.835 \\
\hline No & 14 & $1(1-2.25)$ & 10.43 & & & $1(1-1.5)$ & 10.39 & & & $1(1-2.25)$ & 10.82 & & \\
\hline \multicolumn{14}{|l|}{ Disease outcome } \\
\hline $\begin{array}{l}\text { Remission/ } \\
\text { In progress }\end{array}$ & 21 & $2(1-3.5)$ & 18.93 & 148.50 & 0.755 & $1(1-3.5)$ & 18.50 & 157.50 & 1.000 & $2(1-3.5)$ & 19.02 & 146.50 & 0.706 \\
\hline $\begin{array}{l}\text { Death due to } \\
\text { the tumor }\end{array}$ & 15 & $1(1-3)$ & 17.90 & & & $1(1-2)$ & 18.50 & & & $1(1-3)$ & 17.77 & & \\
\hline
\end{tabular}

OTSSC: oral tongue squamous cell carcinoma. ${ }^{*}$ Non-parametric Mann-Whitney test (U). **(Brandwein-Gensler et al., 2005). 
of oral cancer.

PDPN participates in several effector pathways that, in turn, influence microtubule and actin pool movement in the cellular cytoskeleton, mediated by Rho GTPases and by the Rock signaling pathway (18). Thus, PDPN expression in tumor cells contributes to the increased mobility of epithelial cells, which can occur both as a single cell and in the form of collective cell migration (18).

Li et al. (19) investigated the role of PDPN as an OTSCC invasion promoter through cytoskeletal remodeling, Rho GTPases and metalloproteinases (MMPs). The authors observed the PDPN is involved in the invasion process both in tissue specimens and in cell lines, and that, when PDPN was silenced, cell invasion decreased, indicating that OTSCC invasion is related to and mediated by this protein. Interestingly, these authors reported that increased PDPN expression in some cell lines induced a shift from an epithelial to mesenchymal phenotype, whereas in other strains, PDPN silencing did not influence the expression of EMT markers. In the present study, a statistically significant difference between PDPN immunoexpression and the worst Brandwein-Gensler et al. (6) histological invasion patterns in both LLSCC and OTSCC was detected, suggesting that PDPN is involved in greater dissociation and cellular motility, facilitating neoplastic cell migration. Both membrane and cytoplasm PDPN expression were higher in worse OTSCC invasion patterns, whereas in LLSCC a greater expression was observed only in cytoplasmic PDPN. These findings may suggest that the simultaneous expression in cytoplasm and membrane enhances the migration of neoplastic cells in OTSCC, as it was observed that most cases of OTSCC presented the worst pattern invasion compared to LLSCC. In addition, it may indicate a higher propensity for tumor progression in OTSCC and can be attributed to the presence of PDPN at both protein and mRNA levels (7).

Regarding metastasis, no statistically significant difference was observed between lymph node metastasis and PDPN immunoexpression in LLSCC and OTSCC cases in the present study. Similarly, de Vicente et al. (20) found no significant association between PDPN immunoexpression and lymph node metastasis in OTSCC cases, and also observed that the highest PDPN expression was detected in cases of tongue and floor of the mouth $\mathrm{SCC}$, suggesting that this increased PDPN expression is due to the fact that most of their cases were classified as T1-T2, with a high proportion of well differentiated tumors. However, most of the OTSCC cases in the present study were classified as T2-T3 and higher median cytoplasmic PDPN values were observed in larger tumors (T3 and T4) in both LLSCC and OTSCC, suggesting that PDPN is involved in the migration process even in larger tumors.

In the present study, cells expressing PDPN displayed certain peculiarities. Focal expression was observed in island/ nest and compressive area peripheries, with low or absent expression in the central regions, while some dissociated cells, often not noticed in routine HE analyses, showed strong staining on the invasive front. This was also observed by Prasad et al. (7) when evaluating PDPN expression in different stage OTSCC cases, and by Rodrigo et al. (21) when evaluating PDPN expression in the development and progression of laryngeal SCC. This strengthens the theory that PDPN plays a role in collective tumor invasion, and not through complete EMT. PDPN expression in the tumor nest periphery suggests cytoskeleton alterations, promoting higher proliferation and self-renewal capacity, whereas central cells are suggested as being involved in the terminal differentiation of their maturation, where they are collectively transported until reaching metastatic levels in the tumor (15). It can be hypothesized that PDPNstained dissociated cells are undergoing EMT by means of PDPN activation, where their overexpression can induce phosphorylation of the ezrin, radixin and moesin (ERM) family of proteins, or through the activation of Rho GTP kinases. The consequent effectors (Rac-1, Rho-A and cdc42) of the pathway stimulate actin polymerization, leading to philopodia formation $(11,13,22)$.

Twist exerts its multiple biological effects (angiogenesis, resistance to chemotherapy, metastasis and senescence) through several downstream pathways, acting as a transcription factor that governs the expression of a number of target genes (such as N-CADHERIN, E-CADHERIN, ARF, P53 and CD24) in the nucleus or modulating the function of effectors (such as VEGF, mTOR, Bcl2, p53 and Bmi1) at the protein level in the cytoplasm (23). When evaluating associations between Twist expression and histopathological characteristics of patients presenting oral SCC, Wushou et al. (24) found a significant association between Twist immunoexpression and the presence of metastasis, advanced stages, and moderately and poorly differentiated tumors. In addition, a relationship between recurrence and Twist immunoexpression was also detected. In the present study, however, no significant difference was observed between Twist immunoexpression and either clinical tumor parameters or the histological BrandweinGensler et al. (6) risk scores in LLSCC and OTSCC cases. Analyzing the categories as isolated variables, however, a trend towards a statistically significant difference between nuclear expression and the worst histological invasion patterns as classified by the Brandwein-Gensler et al. (6) grading ( $p=0.054)$ in OTSCC cases was observed.

A possible explanation for the low Twist expression detected in both LLSCC and OTSCC, considering its expression as an isolated variable, is to consider EMT as a spectrum of phenotypes in which tumor cells present 
a great plasticity during their invasion and migration process (25). Thus, it would be possible to assume that tumor cells do not tend to complete the transition from their epithelial phenotype to a mesenchymal phenotype, remaining in a partial EMT. In this context, Jensen et al. (25) performed 3D confocal microscopy analyses to assess whether tumor cells that appear as single and isolated in histological sections were actually isolated cells instead than cells connected by finger-like projections to a larger tumor island, not shown in the section plane. The authors observed that few cells, apparently unique, were actually isolated, and that most were part of the postulated fingerlike projections. For these authors, these findings confirm that OTSCC tend to migrate collectively, through a so-called collective invasion, and not predominantly as single cells. This could support the theory of a partial EMT, where cells migrate as multicellular groups, and where some of these cells undergo partial EMT, possibly guided by PDPN, as observed in the immunohistochemical analysis carried out herein, where PDPN staining was predominantly observed in the peripheries of the tumor islands.

Statistically significant correlations between PDPN membrane expression and general and cytoplasmic Twist mechanisms that highlight the epithelial cell plasticity theory proposed by Renart et al. (11). Their proposed model for PDPN involvement in EMT is that the main function of PDPN would be to drive the mobility of neoplastic cells by interacting with ERM and Rho-GTPases proteins. Depending on the overall and effective cell cohesion, this mobility will either be of the individual mesenchymal type, facilitating EMT, or collective, either without EMT or with partial EMT.

Moreover, contrary to PDPN, Twist, although exhibiting low staining in the LLSCC and OTSCC cases evaluated herein, was also expressed in all island and tumor nest regions (peripheral and central). Tran et al. (26), on the intriguing presence of various EMT inducers such as Snail, Twist and Zeb, investigated the functional motif of the simultaneous presence of multiple EMT inducers in various epithelial and human carcinoma cell lines, since they are often expressed at the same time and in the same cells, especially in cancers. These authors observed a possible inverse transcriptional linkage between Snail1 and Twist1 expressions during EMT induction, and that Snail1 expression was unique in contributing to the onset of EMT, whereas Twist1 cooperated temporarily to maintain a late EMT. This may justify the low Twist expression observed in most of the SCC cases evaluated in the present study, suggesting that EMT may not have been in its late state, and that a high expression of Snail and other EMT inducers may also be present. Other studies investigating the simultaneous expression of these two EMT markers, alongside PDPN, in LLSCC and OTSCC cases could further clarify the interaction of these proteins with the metastatic progression of tumor cells.

OTSCC and LLSCC display different clinical characteristics that reflect their biological behavior and prognosis, the former characterized by a high rate of local invasion and cervical metastasis, directly affecting prognosis, with a five-year survival rate of only $50 \%$, while the latter usually presents lower lymph node metastasis rates and a good prognosis, with an average five-year survival rate ranging from 80 to $90 \%(2,27)$. With this in mind, no statistically significant differences were observed. Thus, the different biological behavior of these lesions at the two evaluated anatomical sites seems not to be linked to Twist and PDPN expression.

In summary, this study demonstrated, for the first time, that PDPN expression is inversely related to Twist in LLSCC cases, and that both PDPN and Twist are correlated to a worse invasion pattern in both LLSCC and OTSCC cases, but not related to the different biological behaviors of SCC in the two different anatomical sites evaluated herein. In addition, the PDPN and Twist relationship in OTSCC cases may be more linked to a partial transition from the epithelial to the mesenchymal phenotype, instead of a complete transition.

\section{Resumo}

0 objetivo deste estudo foi realizar uma análise comparativa das imunoexpressões de podoplanina (PDPN) e Twist em carcinomas de células escamosas de lábio inferior e língua oral (CCELI e CCELO, respectivamente). As imunoexpressões de PDPN e Twist foram avaliadas semi-quantitativamente através da análise do front invasivo, das áreas compressivas, das grandes ilhas e ninhos e das células dissociadas dos carcinomas escolhidos. Suas associações estatísticas e correlações com características clínico-patológicas foram verificadas pelos testes de Mann-Whitney e Spearman. A expressão de Twist foi baixa nos dois carcinomas, com marcação $<25 \%$ no front invasivo. Diferenças significativas foram observadas para CCELI $(p=0,032)$ e CCELO $(p=0,025)$ em relação à imunoexpressão de PDPN em relação aos piores padrões de invasão determinados por um sistema de gradação histológica de malignidade. Também foram observadas correlações negativas estatisticamente significantes entre a expressão membranar de PDPN e as expressões geral $(r=-0,356, p=0,024)$ e citoplasmática do Twist $(r=-0,336$; $p=0,034)$ no CCELI. Sugere-se que o Twist e o PDPN estejam associados a um padrão de invasão mais agressivo nos casos de CCELI e CCELO, mas não relacionados aos diferentes comportamentos biológicos nesses sítios anatômicos. Também foi observado que a expressão membranar de PDPN está inversamente relacionada à expressão geral e citoplasmática de Twist em casos de CCELI.

\section{Acknowledgements}

The work was supported by the Brazilian National Council for Scientific and Technological Development (CNPq) and the Coordination for the Improvement of Higher Education Personnel (CAPES). 


\section{References}

1. Olaleye 0 , Ekrikpo U, Lyne 0 , Wiseberg J. Incidence and survival trends of lip, intra-oral cavity and tongue base cancers in south-east England. Ann R Coll Surg Engl 2015;97:229-234.

2. Zheng $L$, $L i N$, Guo F, Jian $X C$, Jiang $\mathrm{CH}_{\text {, Yin }} \mathrm{P}$ et al. Twist-related protein 1 enhances oral tongue squamous cell carcinoma cell invasion through $\beta$-catenin signaling. Mol Med Rep 2015;11:2255-2261.

3. Hesse $K$, Satzger I, Schacht V, Köther B, Hillen U, Klode J et al. Characterisation of prognosis and invasion of cutaneous squamous cell carcinoma by podoplanin and e-cadherin expression. Dermatology 2017;232:558-565.

4. Zang C, Liu X, Li B, He Y, Jing S, He $Y$ et al. IL-6/STAT3/TWIST inhibition reverses ionizing radiation-induced EMT and radioresistance in esophageal squamous carcinoma. Oncotarget 2017;8:11228-11238.

5. Ozturk K, Gode S, Erdogan U, Akyildiz S, Apaydin F. Squamous cell carcinoma of the lip: survival analysis with long-term follow-up. Eur Arch Otorhinolaryngol 2015;272:3545-3550.

6. Brandwein-Gensler M, Teixeira MS, Lewis CM, Lee B, Rolnitzky L, Hille JJ et al. Oral squamous cell carcinoma histologic risk assessment, but not margin status, is strongly predictive of local disease-free and overall survival. Am J Surg Pathol 2005;29:167-178.

7. Prasad B, Kashyap B, Babu GS, Kumar GR, Manyam R. Expression of podoplanin in different grades of oral squamous cell carcinoma. Ann Med Health Sci Res 2015;5:299-304.

8. da Silva SD, Alaoui-Jamali MA, Soares FA, Carraro DM, Brentani HP, Hier M et al. TWIST1 is a molecular marker for a poor prognosis in oral cancer and represents a potential therapeutic target. Cancer 2014;120:352-362.

9. Deryugina El, Zajac E, Zilberberg L, Muramatsu T, Joshi G, Dabovic $B$ et al. LTBP3 promotes early metastatic events during cancer cell dissemination. Oncogene 2018;37:1815-1829.

10. Sharma A, Boaz $K$, Natarajan S. Understanding patterns of invasion: a novel approach to assessment of podoplanin expression in prediction of lymph node metastasis in oral squamous cell carcinoma. Histopathology 2017;72:672-678.

11. Renart J, Carrasco-Ramírez P, Fernández-Muñoz B, Martín-Villar $E_{1}$ Montero L, Yurrita $M M$, et al. New insights into the role of podoplanin in epithelial-mesenchymal transition. Int Rev Cell Mol Biol 2015;317:185-239.

12. Etemad-Moghadam $\mathrm{S}$, Alaeddini M. Pattern of invasion in squamous cell carcinomas of the lower lip and oral cavity. J Oral Biol Craniofacial Res 2017;7:167-170.

13. Swain N, Kumar SV, Routray S, Pathak J, Patel S. Podoplanin - a novel marker in oral carcinogenesis. Tumour Biol 2014;35:8407-8413.

14. Wong IY, Javaid $S$, Wong EA, Perk S, Haber DA, Toner M, et al. Collective and individual migration following the epithelial-mesenchymal transition. Nat Mater 2014;13:1063-1071.
15. Assao A, Nonogaki S, Lauris JRP, Carvalho AL, Pinto CAL, Soares FA, et al. Podoplanin, ezrin, and Rho-A proteins may have joint participation in tumor invasion of lip cancer. Clin Oral Investig 2017;21:1647-1657.

16. Garcia AS, Assao A, Carvalho AL, Soares FA, Kowalski LP, Oliveira DT. The stem cell markers expression CD44v6 and podoplanin in lip cancer: clinical significance. Virchows Arch. 2019;474:745-754.

17. Rasti $A$, Madjd Z, Abolhasani M, Mehrazma M, Janani L, Saeednejad Zanjani L, et al. Cytoplasmic expression of Twist1, an EMT-related transcription factor, is associated with higher grades renal cell carcinomas and worse progression-free survival in clear cell renal cell carcinoma. Clin Exp Med. 2018;18:177-190.

18. Gissi DB, Gabusi A, Tarsitano A, Luccarini L, Morandi L, Montebugnoli L. Podoplanin expression as a predictive marker of dysplasia in oral leukoplakia. J Craniomaxillofac Surg 2018;46:759-764.

19. Li Y-Y, Zhou C-X, Gao Y. Podoplanin promotes the invasion of oral squamous cell carcinoma in coordination with MT1-MMP and Rho GTPases. Am J Cancer Res 2015:5:514-529.

20. de Vicente JC, Santamarta TR, Rodrigo JP, Garcia-Pedrero JM, Allonca $\mathrm{E}, \mathrm{Blanco-Lorenzo} \mathrm{V}$. Expression of podoplanin in the invasion front of oral squamous cell carcinoma is not prognostic for survival. Virchows Arch 2015;466:549-558.

21. Rodrigo JP, Garcia-Carracedo D, González MV, Mancebo G, Fresno MF, Garcia-Pedrero J. Podoplanin expression in the development and progression of laryngeal squamous cell carcinomas. Mol Cancer 2010;9:48.

22. Martín-Villar E, Megías D, Castel S, Yurrita MM, Vilaró S, Quintanilla M. Podoplanin binds ERM proteins to activate RhoA and promote epithelial-mesenchymal transition. J Cell Sci 2006;119:4541-4553.

23. Zhao Z, Rahman MA, Chen ZG, Shin DM. Multiple biological functions of Twist1 in various cancers. Oncotarget 2017;8:20380-20393.

24. Wushou A, Pan HY, Liu W, Tian Z, Wang LZ, Shali S, Zhang ZY. Correlation of increased twist with lymph node metastasis in patients with oral squamous cell carcinoma. J Oral Maxillofac Surg 2012;70:1473-1479.

25. Jensen DH, Reibel J, Mackenzie IC, Dabelsteen E. Single cell migration in oral squamous cell carcinoma - possible evidence of epithelialmesenchymal transition in vivo. J Oral Pathol Med 2015;44:674-679.

26. Tran DD, Corsa CA, Biswas H, Aft RL, Longmore GD. Temporal and spatial cooperation of Snail1 and Twist1 during epithelial-mesenchymal transition predicts for human breast cancer recurrence. Mol Cancer Res 2011;9:1644-1657.

27. Santos HB, Silva AL, Cavalcante LH, Alves PM, Godoy GP, Nonaka CF. Histopathological grading systems and their relationship with clinical parameters in lower lip squamous cell carcinoma. Int J Oral Maxillofac Surg 2014;43:539-545.
Received April 1, 2020

Accepted July, 15, 2020 